\title{
Erratum to: Optimal Maize Ripeness by Application of Dynamic Ripening and Analysis (DRA) System
}

System Biological Expression for Exactly Planning the Processes and Carrying out the Harvest, Location Suitability, Ripeness-Specific, Highly Efficient Type and Choice of Variety by Means of Silage Maize Ripeness Index (SRI) in Maize Cultivation

\section{Reinhard Amler ${ }^{1}$}

Published online: 8 January 2021

(c) Springer-Verlag GmbH Deutschland, ein Teil von Springer Nature 2021

\section{Erratum to:}

Gesunde Pflanzen 2020

https://doi.org/10.1007/s10343-020-00528-0

The original version of this article unfortunately contained a mistake. The presentation of Fig. 1 and 3 were incorrect. The corrected figures are given below.

The original article has been corrected. 


\section{Reference ripeness time point (SRI of 2,8)}

Navigation instrument for a product security concept in maize cultivation by standardizing the ecophysiologically optimal maize ripeness of genotype and phenotype in harmony with economy and ecology, indicator of the ripeness and stress stability of maize varieties for the purpose of reducing the maize range through needs-based selection and precise risk assessment of climate changes

$$
\text { † }
$$

optimal harvest time (silage ripeness, $\mathrm{SRI}=>2,6$ )

$$
\text { 才 }
$$

correct harvest time (harvest ripeness at the maximum possible SRI)

$$
\uparrow
$$

Control of the ripening dynamics from grain to residual plant using 3 ripening methods $(\mathrm{K} / \mathrm{R}, \mathrm{K} / \mathrm{G}, \mathrm{G} / \mathrm{S})$

$$
\text { is }
$$

Cropmanagement using phenological ripeness, stress and selection indicators, the Silage maize Ripeness Index (SRI)

\section{Cultivation of environmentally and ripeness stable maize varieties ז}

Use-specific variety selection with needs-based reduction of the maize range

Environmental, animal and consumer protection (fermentation juice, mycotoxin, nitrogen pollution of the soil) as well as high social acceptance of maize cultivation and risk assessment of climatic changes

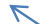

\section{efficient, environmentally equitable and sustainable utilization of maize for all uses}

Phenotyping of yield increase and stabilization as well as determination of the order of harvest of the maize fields

$$
\downarrow
$$

biotic and abiotic stress tolerance and site suitability

$$
\checkmark
$$

Ripeness-specific variety type (very different from ripeness, stay green

\section{Reproducibility of variety and resistance performance $\checkmark$}

Product and quality assurance through indicator-based plant health (mycotoxin, carotene) in the vital area of the residual plant with a DM content of $23 \%$ and less<smiles>[C]1C=C1</smiles>

Maximum feed intake of healthy, tasty and structurally rich maize silage as well as methane gas production through fermentationbiologically highly digestible substrate and grain production

$$
\checkmark
$$

Fig. 1 Systems biology of the ecophysiological optimal maize ripeness in the DRA system

Fig. 3 Reference ripeness point (SRI of 2.8) of optimal maize ripeness, site suitability and reproducibility of variety as well as resistance performance for all directions of use in harmony with economy and ecology

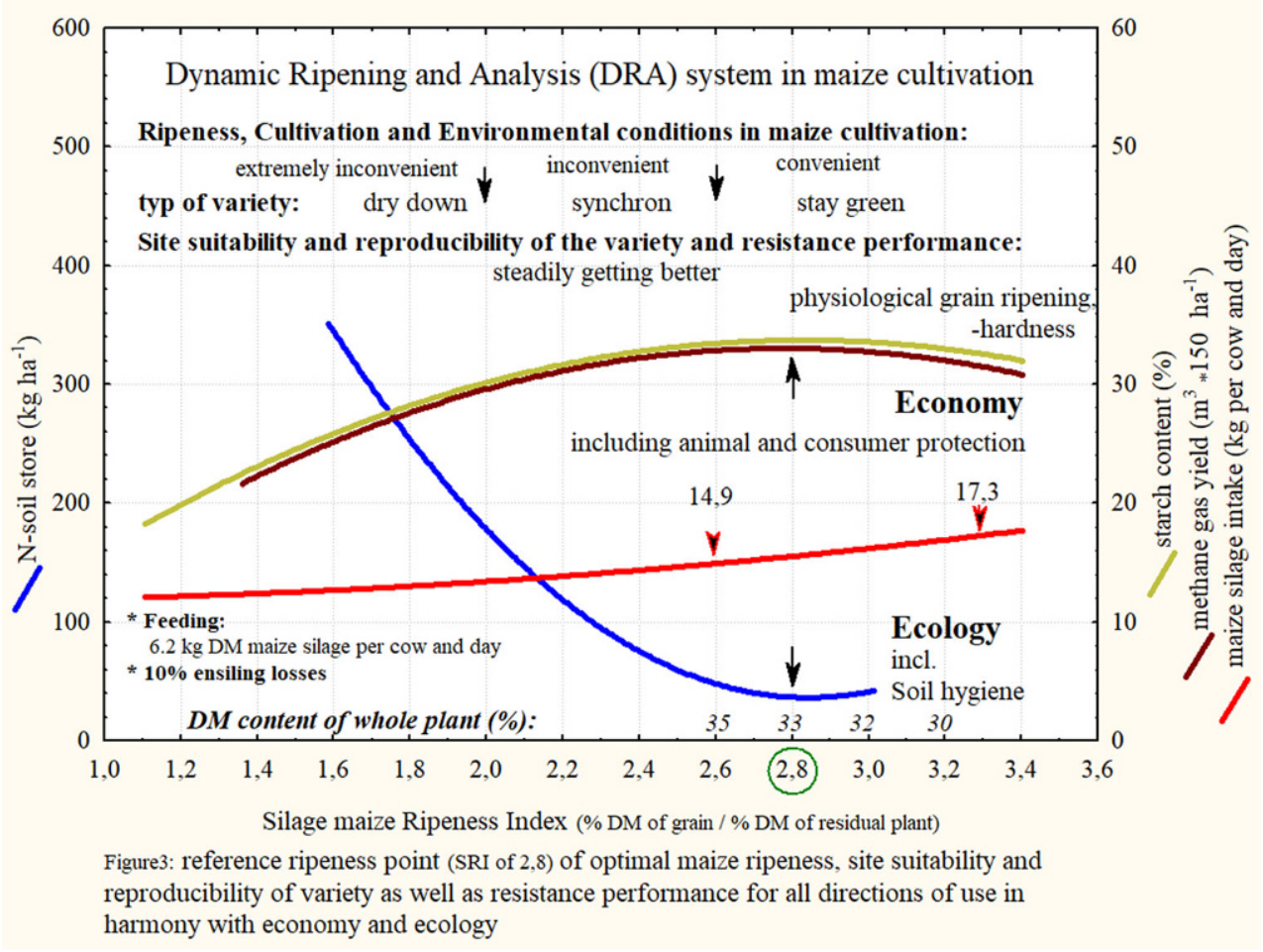


The correct version of the legend to Fig. 2 is given below.

Fig. 2 Crop management and ripeness assessment of the varieties for silage, energy and grain maize according to the degree of ripeness and ripeness ratio

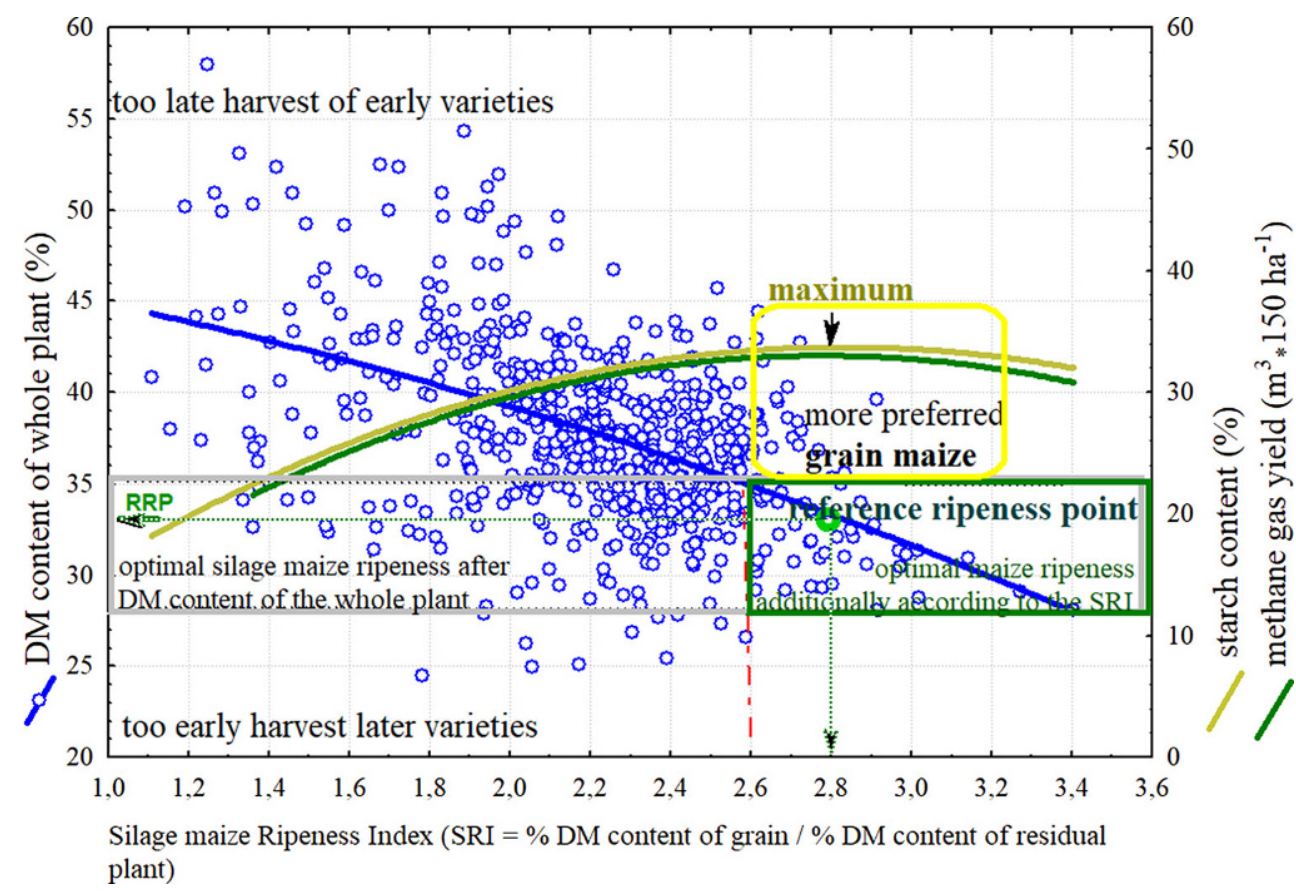

